\title{
COVID-19 Serologic Testing Among the Highest Risk Healthcare Workers
}

J Gen Intern Med 36(4): 1164-5

DOI: $10.1007 / \mathrm{s} 11606-020-06462-1$

(C) Society of General Internal Medicine 2021

\section{BACKGROUND}

Early in the coronavirus disease 2019 (COVID-19) pandemic, data suggested that healthcare workers on the frontlines of patient care are at especially high risk of contracting severe acute respiratory syndrome coronavirus 2 (SARS-CoV-2) and developing COVID-19. ${ }^{1,2}$ The first confirmed case to present to our institution was on March 12th, 2020. Our institution initiated a personal protective equipment (PPE) policy of continuously wearing N95 masks plus eye protection for those in high-risk areas (i.e., COVID-19 units where aerosolizing procedures are performed) on March 16th, 2020.

\section{OBJECTIVE}

The objective of this study is to determine, in the setting of our continuous PPE policy, the proportion of highest risk healthcare clinicians, defined as in-hospital clinicians who are involved in aerosolizing procedures for COVID-19-positive patients, who test positive for SARS-CoV-2 antibodies.

\section{METHODS}

A convenience sample of healthcare workers at an academic medical center in southern New Jersey were included. Inclusion criteria were as follows: (1) age $\geq 18$ years; (2) physician, physician assistant, advance practice nurse, nurse, technician, or other patient facing in-hospital support staff involved in aerosolizing procedures (e.g., endotracheal intubation) for known COVID-19-positive patients. This study was approved by our Institutional Review Board. All potential subjects received an email discussing enrollment. Participants provided written informed consent and received a second email containing a link to complete an online research questionnaire inquiring about demographics (e.g., sex, age), work type, work area, previous COVID-19 testing, type of test (if applicable), test result (if applicable), and previous suspected COVID-19 symptoms since March 1, 2020.

Received October 13, 2020

Accepted December 13, 2020

Published online January 19, 2021
Between June 10 and August 31, 2020, subjects underwent serology testing for presence of SARS-CoV-2 antibodies using the Roche (Basel, Switzerland) Elecsys ${ }^{\circledR}$ Anti-SARSCoV-2 immunoassay. This immunoassay provides a single qualitative result of either positive or negative for the presence of antibodies for SARS-CoV-2 (i.e., IgG, IgM, and/or IgA). If the results of the Elecsys ${ }^{\circledR}$ Anti-SARS-CoV-2 immunoassay were negative, the subject was determined to be SARS-CoV-2 antibody negative. Samples which tested positive for SARSCoV-2 antibodies on the Elecsys ${ }^{\circledR}$ immunoassay were further tested on the EUROIMMUN SARS-CoV-2 ELISA kit (Lübeck, Germany) to confirm seroconversion. We calculated the proportion of subjects who were antibody positive along with binomial exact $95 \%$ confidence intervals.

Table 1 Subject Characteristics

\begin{tabular}{|c|c|c|c|}
\hline Variable & $\begin{array}{l}\text { All subjects } \\
(n=172)\end{array}$ & $\begin{array}{l}\text { IgG negative } \\
(n=163)\end{array}$ & $\begin{array}{l}\text { IgG positive } \\
(n=9)\end{array}$ \\
\hline Age (SD) & $40(11)$ & $40(11)$ & $38(14)$ \\
\hline Female $(n(\%))$ & $115(67)$ & $109(67)$ & $6(67)$ \\
\hline \multicolumn{4}{|l|}{ Occupation $(n(\%))$} \\
\hline Physician & $60(35)$ & $58(36)$ & $2(22)$ \\
\hline Advanced & $26(15)$ & $26(16)$ & 0 \\
\hline \multicolumn{4}{|l|}{ practitioner nurse } \\
\hline Nurse & $68(40)$ & $63(39)$ & $5(56)$ \\
\hline Respiratory & $11(6)$ & $10(6)$ & $1(11)$ \\
\hline \multicolumn{4}{|l|}{ therapist } \\
\hline Technician & $3(2)$ & $2(1)$ & $1(11)$ \\
\hline Other support & $4(2)$ & $4(2)$ & 0 \\
\hline staff & & & \\
\hline \multicolumn{4}{|c|}{ Primary work locations } \\
\hline Emergency & $116(67)$ & $113(69)$ & $3(33)$ \\
\hline \multicolumn{4}{|l|}{ department } \\
\hline Intensive care unit & $70(41)$ & $68(42)$ & $2(22)$ \\
\hline Step down unit & $11(6)$ & $11(6)$ & \\
\hline Floor & $12(7)$ & $11(7)$ & $1(11)$ \\
\hline Operating room & 32 (19) & 31 (19) & $1(11)$ \\
\hline Other & $31(18)$ & $29(18)$ & $2(22)$ \\
\hline \multicolumn{4}{|c|}{ Reported previous symptoms $(n(\%))$} \\
\hline Fever & $14(8)$ & $7(4)$ & $7(78)$ \\
\hline Myalgias & $22(13)$ & $16(10)$ & $6(67)$ \\
\hline Cough & $30(17)$ & $24(15)$ & $6(67)$ \\
\hline Sore throat & $21(12)$ & $19(12)$ & $2(22)$ \\
\hline Rhinorrhea & 29 (17) & $26(16)$ & $3(33)$ \\
\hline $\begin{array}{l}\text { Loss of sense of } \\
\text { smell or taste }\end{array}$ & $8(5)$ & $3(2)$ & $5(56)$ \\
\hline Dyspnea & $7(4)$ & $3(2)$ & $4(44)$ \\
\hline Diarrhea & $15(9)$ & $13(8)$ & $2(22)$ \\
\hline $\begin{array}{l}\text { Previous RT-PCR } \\
\text { testing }(n(\%))\end{array}$ & $26(15)$ & $18(11)$ & $8(89)$ \\
\hline
\end{tabular}

$S D$, standard deviation; $R T-P C R$, reverse transcriptase polymerase chain reaction 


\section{FINDINGS}

Of 614 potential subjects who were sent an enrollment email, 189 responded and 172 ultimately completed the serology testing. Nine of the 172 (5.2\% [95\% CI 2.4 to 9.7\%]) subjects were antibody positive. Table 1 displays the demographics of the cohort. Seven subjects who were positive on both assays reported prior symptoms and were confirmed to have had a previously positive SARS-CoV-2 reverse transcriptase polymerase chain reaction (RT-PCR) test. The median (range) time between the positive RT-PCR tests and serology testing was 62 (34-105) days. One subject who reported prior symptoms with two confirmed negative RT-PCR tests was positive on both assays, while one subject who did not report prior symptoms and did not have a prior RT-PCR test was positive on Elecsys ${ }^{\circledR}$ and $\operatorname{IgG}$ borderline on the ELISA (which was confirmed borderline on 2-week repeat testing).

\section{DISCUSSIONS}

Prior to June 10, 2020, our institution hospitalized and treated over 620 confirmed COVID-19 patients and approximately 950 in total between March 12 and August 31, 2020. However, only $5 \%$ of this highest risk clinician cohort tested positive for SARS-CoV-2. Furthermore, we are unable to determine if these subjects were infected with SARS-CoV-2 at work or from the community; thus, healthcare-related infection may be substantially lower than 5\% among this population. We acknowledge there exists the possibility of false negative results or that some employees may have been infected and not yet seroconverted. However, we are reassured of the accuracy of the test results given all subjects who had a positive RT-PCR test were found to be antibody positive (on both the Roche and EUROIMMUN). Furthermore, given we used a convenience sample, it is possible that those who opted into the study are not fully representative of this population. For example, those that choose to participate in this study may also be more likely to fully adhere to the PPE protocol at work and social distancing guidelines when in the community. However, all 172 included subjects were involved in high-risk procedures, suggesting that, despite high-risk exposures, healthcare-related infection rates may be low in institutions that implement continuous PPE policies.

Snehal Gandhi, $M D^{1}$

Christine C. Winn, FACHE ${ }^{1}$

Monica Ianosi-Irimie, $\mathrm{MD}, \mathrm{PhD}^{2}$

Tina Bocker Edmonston, $M D^{2}$

Raquel Nahra, $M D^{3}$

Brian W. Roberts, $M D, M S c^{4}$

${ }^{1}$ The Department of Medicine, Cooper University Hospital, Cooper Medical School of Rowan University,

Camden, NJ, USA

${ }^{2}$ The Department of Pathology, Cooper University Hospital, Cooper Medical School of Rowan University,

Camden, NJ, USA

${ }^{3}$ The Department of Medicine, Division of Infectious Disease, Cooper University Hospital, Cooper Medical School of Rowan University,

Camden, NJ, USA

${ }^{4}$ The Department of Emergency Medicine, Cooper University Hospital, Cooper Medical School of Rowan University, Camden, NJ, USA

Corresponding Author: Brian W. Roberts, MD, MSc; The Department of Emergency Medicine, Cooper University Hospital, Cooper Medical School of Rowan University, Camden, NJ, USA (e-mail: roberts-brian-w@cooperhealth.edu).

\section{Compliance with Ethical Standards:}

Conflict of Interest: The authors declare that they have no conflicts of interests.

\section{REFERENCES}

1. Paterlini M. On the front lines of coronavirus: the Italian response to covid-19. BMJ. 2020;368:m1065.

2. Wang D, Hu B, Hu C, Zhu F, Liu X, Zhang J, et al. Clinical characteristics of 138 hospitalized patients with 2019 novel coronavirus-infected pneumonia in Wuhan, China. JAMA. 2020.

Publisher's Note: Springer Nature remains neutral with regard to jurisdictional claims in published maps and institutional affiliations. 